\title{
Correction: Primary tumor-derived exosomes facilitate metastasis by regulating adhesion of circulating tumor cells via SMAD3 in liver cancer
}

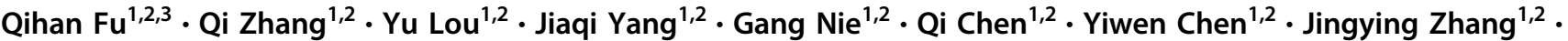 \\ Jianxin Wang ${ }^{1,2} \cdot$ Tao Wei $^{1,2} \cdot$ Hao Qin ${ }^{1,2} \cdot$ Xiaowei Dang ${ }^{4} \cdot$ Xueli Bai ${ }^{1,2} \cdot$ Tingbo Liang $^{1,2}$
}

Published online: 8 May 2019

(c) The Author(s) 2019. This article is published with open access

\section{Correction to: Oncogene 37:6105-6118 \\ https://doi.org/10.1038/s41388-018-0391-0 \\ published online 10 July 2018}

Following publication of this article the Authors noted mislabelling in Fig. 2k. The label ITGA2 had been duplicated and $\mathrm{CDH} 1$ had been omitted. The correct version of the figure is included below.

Open Access This article is licensed under a Creative Commons Attribution 4.0 International License, which permits use, sharing, adaptation, distribution and reproduction in any medium or format, as long as you give appropriate credit to the original author(s) and the source, provide a link to the Creative Commons license, and indicate if changes were made. The images or other third party material in this article are included in the article's Creative Commons license, unless indicated otherwise in a credit line to the material. If material is not included in the article's Creative Commons license and your intended use is not permitted by statutory regulation or exceeds the permitted use, you will need to obtain permission directly from the copyright holder. To view a copy of this license, visit http://creativecommons. org/licenses/by/4.0/.

Xueli Bai

liangtingbo@zju.edu.cn

$\triangle$ Tingbo Liang

shirleybai@zju.edu.cn

1 Department of Hepatobiliary and Pancreatic Surgery, the Second Affiliated Hospital, Zhejiang University School of Medicine, Hangzhou, China

2 Zhejiang Provincial Key Laboratory of Pancreatic Disease, Hangzhou, China

3 Department of Medical Oncology, the Second Affiliated Hospital, Zhejiang University School of Medicine, Hangzhou, China

4 Department of Hepatopancreatobiliary Surgery, the First Affiliated Hospital of Zhengzhou University, Zhengzhou, China 
A

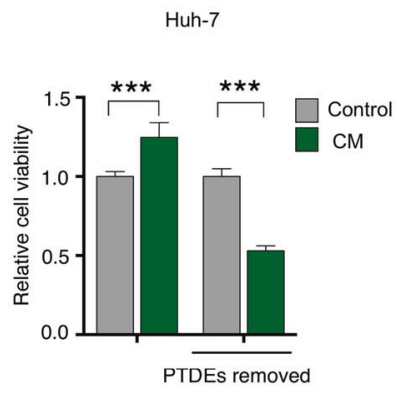

B

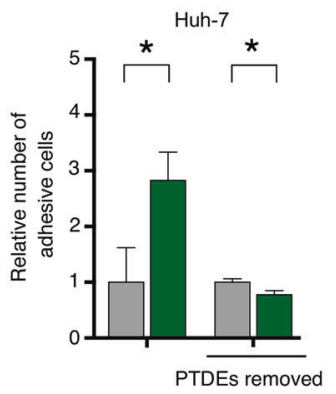

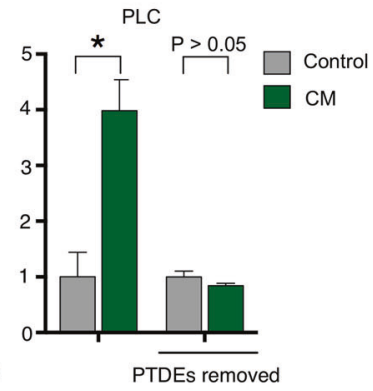

$\mathrm{C}$
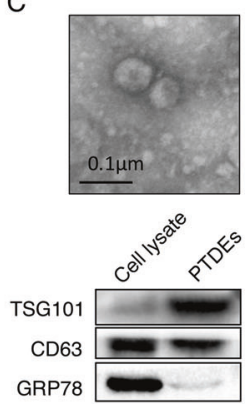

D

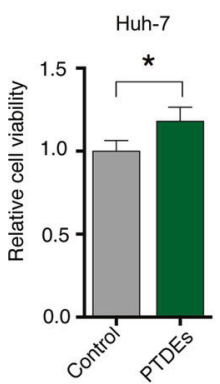

G

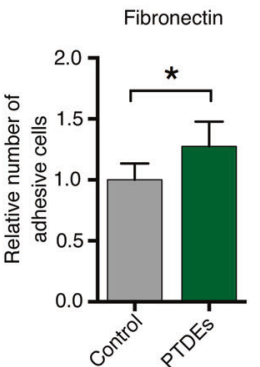

$\checkmark$

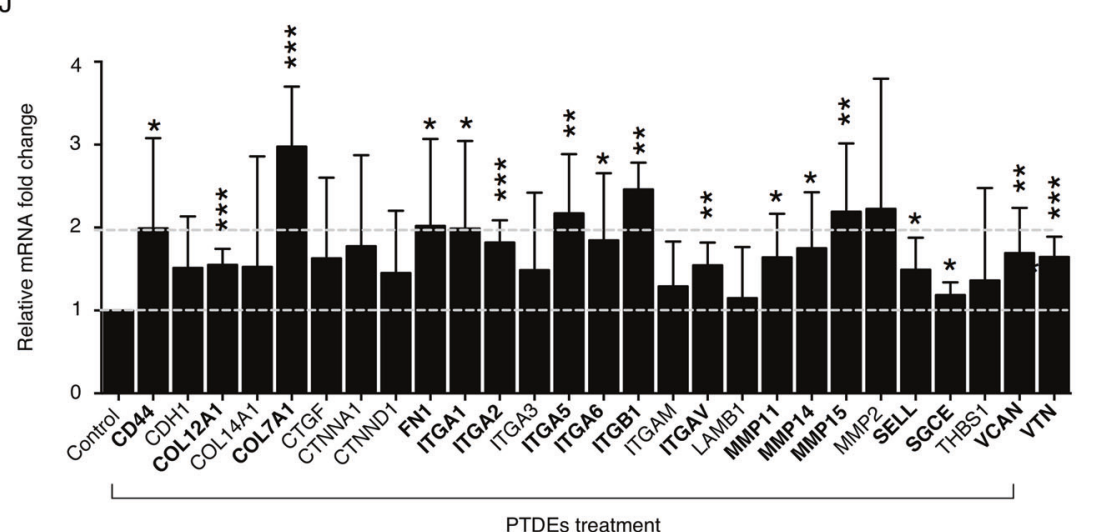

$E$

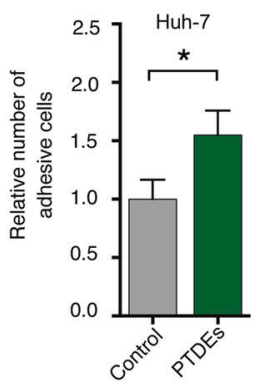

$\mathrm{H}$

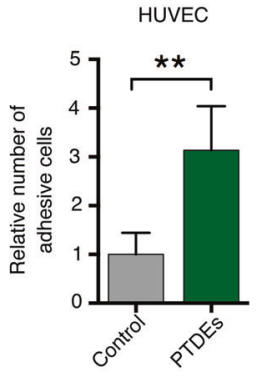

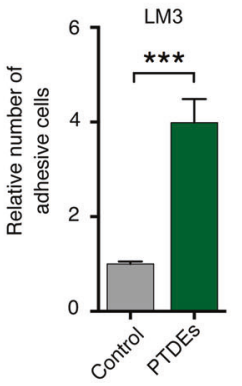

I

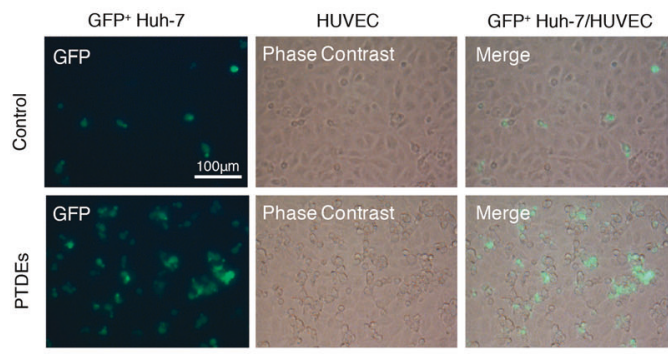

$\mathrm{K}$

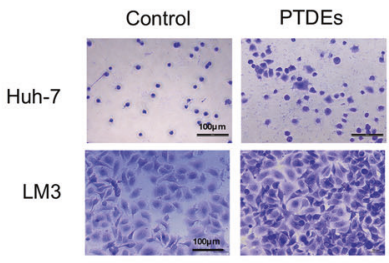

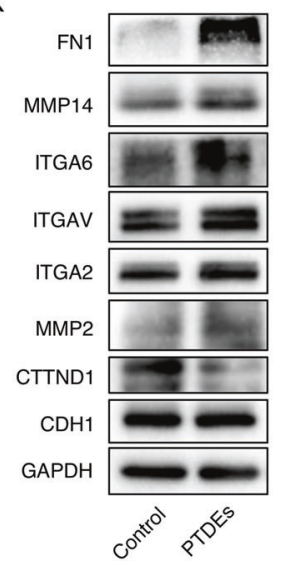

Fig. 1 PTDEs mediate cell proliferation and adhesion. a Huh-7 cells were cultured in indicated medium with or without PTDEs removal for $2 \mathrm{~h}$. Cell viability was determined using CCK-8 assays. b Huh-7 and PLC cells were cultured in the indicated media for $2 \mathrm{~h}$. Number of adhesive cells were counted and compared. $\mathbf{c}$ Visualization of exosomes by transmission electron microscopy. Enriched TST101 and CD63 (exosomes markers) were detected in PTDEs, GRP78 (an endoplasmic reticulum marker) was almost negative. d Huh-7 cells were cultured and treated with or without PTDEs. e, f Huh-7 or LM3 cells were cultured and treated with or without PTDEs. e Statistical analysis of adhesive Huh-7 and LM3 cells exposed to PTDEs. f Representative images for Huh-7 and LM3 cells are shown. g Huh-7 cells were cultured on fibronectin-coated plates and treated with
PTDEs for $2 \mathrm{~h}$. Statistical analysis of adhesive cells are shown. h, i GFP+ Huh-7 cells were cultured on HUVECs-coated plates and treated with PTDEs for $2 \mathrm{~h}$. Representative images and statistical analysis of GFP+ adhesive cells are shown. $\mathbf{j}$ The relative mRNA levels of indicated genes were measured by qRT-PCR in detached Huh-7 cells exposed to PTDEs for $6 \mathrm{~h}$ compared with the cells that did not receive PTDEs. $\mathbf{k}$ The expression of indicated proteins were measured by western blotting in detached Huh-7 Cells exposed to PTDEs for $6 \mathrm{~h}$ compared with the cells that did not receive PTDEs. $\mathbf{a}, \mathbf{b}, \mathbf{d}, \mathbf{e}, \mathbf{g}, \mathbf{h}, \mathbf{j}$ Data are expressed as means $\pm \mathrm{SD}$ of at least three independent experiments. Statistical analysis was performed using unpaired $\mathrm{t}$ test. $* P<0.05, * * P<0.01, * * * P<0.001$ 